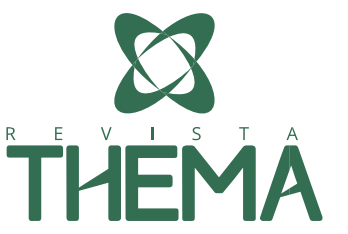

Ciências Humanas

\section{Educação Infantil e o Ensino Fundamental: A Relação entre o Docente e as Teorias sobre o Desenvolvimento Humano}

\section{Child Education and Primary Education: The Relationship Between Teachers and the Theories of Human Development}

Carmen Aparecida Cardoso Maia Camargoํㅜㄹ Marcio Antonio Ferreira Camargo ${ }^{1}$; Virginia de Oliveira Souza ${ }^{2}$

\section{RESUMO}

O presente trabalho faz parte do projeto de pesquisa intitulado "O docente e o desenvolvimento humano: teorias e práticas em um ritual de passagem". O objetivo deste foi investigar as possíveis contribuições que as teorias do desenvolvimento humano de Piaget, Vygotsky, Wallon e Freud podem oferecer aos docentes no processo de transição da Educação Infantil para o Ensino Fundamental, frente às mudanças no âmbito educacional. $\mathrm{O}$ desenvolvimento humano envolve diversos fatores devido à complexidade que o constitui. $\mathrm{O}$ ser humano, ao longo do seu crescimento, possui necessidades físicas, afetivas e intelectuais que se modificam em relação a faixa etária em que esse se encontra. Nesse contexto, percebe-se a importância do estudo do desenvolvimento humano, pois não se pode lidar da mesma forma com uma criança, um adolescente ou um adulto. Essas fases se diferenciam ao mesmo tempo que são interligadas por serem fundamentação da evolução do ser humano. $O$ docente, na escola, ao lado do aluno é um dos participantes estruturantes dessa instituição. Nesse aspecto, tão importante quanto a sua figura, como componente desse todo, é a prática que este exerce em sala de aula. A elaboração dessa se faz fundamental no compartilhamento do conhecimento, no qual o professor atua como mediador. Desse modo, propicia caminhos para a progressão contínua dos alunos em relação aos saberes ministrados, em especial na transição da Educação Infantil para o Ensino Fundamental. A Educação Infantil e o Ensino Fundamental são dois níveis de ensino de extrema importância, não apenas na escolarização das crianças e adolescentes, esses vão muito além. São neles, em meio a componentes curriculares e práticas educativas, que são formados os cidadãos que serão a base da sociedade. Nesse contexto, é essencial considerar a fase do desenvolvimento humano que envolve cada um desses níveis de ensino. Dessa forma, a escola pode viabilizar, dentro do seu processo de ensino e aprendizagem, meios nos quais as singularidades dos alunos sejam respeitadas, sem deixar em segundo plano sua progressão como indivíduo. Sobre a metodologia, utilizou-se a pesquisa qualitativa apoiada em pesquisa bibliográfica descritiva. Para a pesquisa de campo foi utilizada a entrevista estruturada, dirigida a três professoras que atuam nos níveis de ensino mencionados, em uma escola pública de Passos, Minas Gerais. Também se fez uso da observação participante. Utilizou-se a análise de conteúdo como ferramenta para interpretação dos dados da pesquisa, tendo como referência Minayo. A partir dos dados encontrados, observou-se que as intervenções da teoria piagetiana resultam em diferentes possibilidades de contribuição para o desenvolvimento das práticas pedagógicas. Essas práticas visam o desenvolvimento da criança, respeitando suas singularidades. A teoria piagetiana destaca que a elaboração do conhecimento se constitui em meio há alguns processos. $O$ indivíduo está imerso em um processo constante de adaptação de novos conhecimentos. Nesse contexto, tal conhecimento provoca mudanças nos esquemas de adaptação, que necessita incorporar o novo conhecimento

\footnotetext{
1 UEMG - Universidade do Estado de Minas Gerais - Passos/MG - Brasil.

2 Rede Municipal de Educação de Passos, Passos/MG - Brasil.
} 
para organizá-lo junto aos saberes que já possui. Logo, esses processos se fazem permanentes em relação a todas as situações. Demonstrou-se que a forma de intervenção baseada nos jogos e brincadeiras, acrescidas aos componentes curriculares, permite minimizar os desafios encontrados nesse ritual de transição. Como resultado desse trabalho, as evidências reforçam que a formação do docente e a aplicabilidade do conhecimento acadêmico são imprescindíveis à prática pedagógica, no contexto educativo. Sob esse aspecto, a junção da prática docente e dos conhecimentos acadêmicos desencadeia a reflexão das práticas escolares, proporcionando a construção significativa do processo educacional.

Palavras-chave: Educação Infantil. Ensino Fundamental. Desenvolvimento Humano. Prática docente.

\section{ABSTRACT}

The present work is part of the research project titled "The teacher and human development: theories and practices in a ritual of passage". The purpose of this study was to investigate the possible contributions that the human development theories of Piaget, Vygotsky, Wallon and Freud can offer to teachers in the process of transition from Early Childhood Education to Elementary School, in the face of changes in the educational context. Human development involves several factors because of the complexity that constitutes it. The human being, throughout its growth, has physical, affective and intellectual needs that change in relation to the age group in which it is. In this context, one can see the importance of studying human development, because it can 't be treated in the same way with a child, a teenager or an adult. These phases differ at the same time that they are interconnected because they are the foundation of the evolution of the human being. The teacher, in the school, next to the student is one of the structuring participants of this institution. In this aspect, as important as its figure, as a component of this whole, is the practice that it exercises in the classroom. The elaboration of this is fundamental in the sharing of knowledge, in which the teacher acts as mediator. In this way, it provides avenues for the continuous progression of students in relation to the knowledge given, especially in the transition from Early Childhood Education to Elementary Education. Early Childhood Education and Secondary Education are two levels of education of extreme importance, not only in the schooling of children and adolescents, these go much further. It is in them, in the midst of curricular components and educational practices, that the citizens who form the basis of society are formed. In this context, it is essential to consider the stage of human development that involves each of these levels of education. In this way, the school can make possible, within its teaching and learning process, means in which the singularities of the students are respected, without leaving in second plane its progression as individual. On the methodology, was used the qualitative research supported in research descriptive bibliography. For the field research the structured interview was used, directed to three teachers who work at the mentioned teaching levels, in a public school in Passos, Minas Gerais. Participant observation was also used. Content analysis was used as a tool for interpreting research data, using Minayo as a reference. From the data found, it was observed that the interventions of Piagetian theory result in different possibilities of contribution to the development of pedagogical practices. These practices aim at the development of the child, respecting their singularities. Piagetian theory emphasizes that the elaboration of knowledge is in the midst of some processes. The individual is immersed in a constant process of adaptation of new knowledge. In this context, such knowledge causes changes in the patterns of adaptation, which need to incorporate the new knowledge to organize it together with the knowledge already possessed. Therefore, these processes become permanent in relation to all situations. It has been demonstrated that the form of intervention based on games and games, added to the curricular components, allows to minimize the challenges encountered in this ritual of transition. As a result of this work, the evidence reinforces that teacher training and the applicability of academic knowledge are essential to pedagogical practice, in the educational context. In this aspect, the combination of teaching practice and academic knowledge triggers the reflection of school practices, providing significant construction of the educational process.

Keywords: Childhood Education. Elementary School. Humandevelopment. Teachingpractice 


\section{INTRODUÇÃO}

O desenvolvimento humano ocorre gradual e continuamente ao longo da vida. Portanto, na aprendizagem, esse é um fator estruturante. Percebe-se, desse modo, que há uma influência recíproca entre desenvolvimento humano e aprendizagem. Ao crescer, o indivíduo passa por períodos alternados de mudança e estabilidade, dentre os quais está presente o âmbito escolar. Esse ambiente possui uma parte fundamental que o constitui: o docente. Esse profissional da educação deve perceber, em sua formação acadêmica, a relevância de conhecer as teorias sobre odesenvolvimento humano de Piaget, Vygotsky, Wallon e Freud para entrelaçá-las as suas práticas pedagógicas.

Essa relação entre o desenvolvimento humano e a prática docente torna-se ainda mais pertinente no processo de transição da Educação Infantil para o Ensino Fundamental, porque, além de lidar com esse ritual de passagem, que possui rupturas e continuidades, o docente depara-se com a inserção da criança aos seis anos de idade no Ensino Fundamental.

Atualmente, frente as mudanças legislativas, tanto a prática docente (didática e a relação aluno e professor) quanto as práticas pedagógicas (componentes curriculares, planejamento, processo de ensino e aprendizagem e avaliação), nos níveis de ensino mencionados, são objetos de reflexão constante no contexto educativo. Nesse sentido, o conhecimento das teorias sobre o desenvolvimento humano de Piaget, Vygotsky, Wallon e Freud pelo docente denota possibilidades de sucesso no ambiente escolar.

Esse conhecimento se faz válido ao levar em consideração que cada faixa etária possui suas especificidades e que essas estão presentes no processo de ensino e aprendizagem. Desse modo, tão importante quanto ter o conhecimento das teorias de Piaget, Vygotsky, Wallon e Freud, é saber aplicálo por meio das práticas pedagógicas adotadas em sala de aula.

Assim, este estudo teve como principal objetivo investigar as possíveis contribuições que as teorias sobre o desenvolvimento humano de Piaget, Vygotsky, Wallon e Freud podem oferecer aos docentes em relação ao processo de transição da Educação Infantil para o Ensino Fundamental, frente às mudanças no âmbito educacional.

\section{REFERENCIAL TEÓRICO}

A Educação Infantil e o Ensino Fundamental são níveis de ensino que fazem parte da Educação Básica, contudo possuem características distintas. A Educação Infantil oferece práticas educativas com a intenção de propiciar o desenvolvimento integral do ser humano e tem na interdisciplinaridade seu ponto estrutural, além de enfatizar o cuidar e o brincar em meio aos componentes curriculares, de acordo com o Referencial Curricular Nacional da Educação Infantil (BRASIL, 1998).

A Lei de Diretrizes e Bases da Educação Nacional número 9.394 de 20 de dezembro 1996 em seus Artigos 6, 29 e 30 alterados pela Lei número 12.796 de 4 de abril de 2013 estabelecem, respectivamente, que é dever dos pais ou responsáveis matricular a criança a partir dos 4 (quatro) anos de idade na Educação Básica, a Educação Infantil como etapa da educação básica com a finalidade de desenvolver integralmente a criança de até 5 (cinco) anos de idade e que a Educação Infantil deverá ser oferecida em creches para crianças de até 3 (três) anos de idade e pré-escolas para crianças de 4 (quatro) a 5 (cinco) anos de idade. 
O Ensino Fundamental, assim como a Educação Infantil, também sofreu mudanças significativas, no que se refere à legislação. O Artigo número 32 da lei de Diretrizes e Bases da Educação Nacional (LDB), Lei número 9.394 de 20 de dezembro de 1996, foi alterado pela Lei número 11.274 de 6 de fevereiro de 2006, na qual ficou estabelecido o Ensino Fundamental obrigatório com a duração de nove anos ao iniciar-se aos 6 anos de idade.

De acordo com Kramer (2007) deve-se, em um primeiro momento, avaliar qual o papel social da infância, pois essa concepção é construída historicamente de acordo com a sociedade da qual faz parte, na qual a diversidade cultural, social e econômica precisa ser levada em consideração com o intuito de elaborar práticas pedagógicas que valorizarem o brincar, o lúdico, os jogos e a imaginação, para que não se perca a singularidade e o modo peculiar de ver o mundo dessa faixa etária.

Nesse contexto, tornou-se necessário refletir e reelaborar a organização e o planejamento da prática pedagógica com a ampliação do Ensino Fundamental.

A adaptação da criança deve acontecer de maneira gradual e contínua, porque ela vê esse processo, de transição da Educação Infantil para o Ensino Fundamental, apenas como uma progressão no sistema escolar. Porém, suas mudanças são percebidas. É importante para o desenvolvimento da criança, a inserção de novos saberes e novos modos de comportamentos e regras, mas tão importante quanto a apreensão desses novos conceitos é como essa inserção é ministrada.

Entre os referidos níveis de ensino se encontram presentes rupturas na organização do mobiliário da sala de aula, nos componentes curriculares e nas atividades pedagógicas. Outro ponto que merece destaque é a questão do brincar no processo de ensino e aprendizagem. As crianças têm na brincadeira um meio de compreender valores, regras, conhecimentos e cultura. As práticas educativas no Ensino Fundamental vão aos poucos anulando o brincar o que prejudica a transição da Educação Infantil para este nível de ensino.

Segundo Borba (2007) o brincar se faz presente em todo o processo da Educação Infantil, contudo na inserção do Ensino Fundamental o mesmo brincar é associado a oposição do trabalho, uma visão estabelecida culturalmente fora e dentro da escola.

O Ensino Fundamental é uma nova etapa na vida escolar da criança, em especial para as de 6 anos de idade que ingressaram no $1^{\circ}$ ano do referido nível de ensino. Elas deparam-se com mudanças que envolvem todo o ambiente escolar (sala de aula, rotina e componentes curriculares), no qual o processo de alfabetização e letramento, que foi iniciado na Educação Infantil, ganha ênfase e amplitude, pois será a base essencial para os anos seguintes desse nível de ensino.

Dessa maneira, as teorias do desenvolvimento humano surgem como colaboradoras para a compreensão da elaboração da construção do conhecimento pela criança. O período da infância que envolve a transição da Educação Infantil para o Ensino Fundamental é visto de perspectivas diferentes segundo Piaget, Vygotsky, Wallon e Freud.

Segundo Piaget (2002), o estágio pré-operatório (dos 2 aos 7-8 anos) é marcado pelo surgimento da função simbólica e pelo declínio do egocentrismo. A criança já tem a noção de que é um objeto que faz parte do meio em que está inserida, porém, suas estruturas mentais ainda não permitem que construa um pensamento lógico para conceber outros pontos de vista além do próprio, fator percebido na linguagem usada pela criança nessa fase. Entretanto, essa perspectiva será superada à medida 
em que a criança relaciona realidade e lógica. "A criança não está sendo egoísta; ela apenas pensa (supõe) que todos veem o mundo como ela vê." (BEE, 2011, p. 175).

A conquista da linguagem é outro ponto crucial nesse estágio. Inicialmente, essa tem a função de viabilizar a comunicação com o outro. Entretanto, aliada a função representativa (simbólica), adquirida pela progressão do pensamento, a linguagem passa a ser um modo de expressão de ações e idéias, ao que foi vivenciado de forma concreta. A linguagem é influenciada pelo pensamento que tem nessa sua representação verbal.

Com decorrência do aparecimento da linguagem, o desenvolvimento do pensamento se acelera. No início do período, o pensamento exclui toda a objetividade, a criança transforma o real em função dos seus desejos e fantasias (jogo simbólico); posteriormente, utiliza-o como referencial para explicar o mundo real, a sua própria atividade, seu eu e suas leis morais; no final do período, passa a procurar a razão causal e finalista de tudo (é a fase dos famosos "porquês"). É um pensamento mais adaptado ao outro e ao real. (BOCK; FURTADO; TEIXEIRA, 2008, p. 121).

Jean Piaget, psicólogo e biólogo, tinha como foco principal do seu trabalho o estudo sobre a elaboração e o desenvolvimento do conhecimento na mente humana. Seu vasto trabalho é resultado de inúmeras pesquisas que vez ao longo de sua carreira. Seu trabalho foi voltado para o estudo da origem do conhecimento no ser humano.

De acordo com Fontana e Cruz (1997), Piaget procurou elaborar a gênese do conhecimento ao desenvolver uma psicologia genética que tratasse cientificamente essa construção do saber, ao aliar aspectos biológicos e filosóficos de maneira empírica, por meio da formulação de teorias e metodologias, na qual encontrou caminhos na psicologia do desenvolvimento.

Tal modo de conceber o funcionamento cognitivo é decorrente do modelo biológico em que Piaget se baseou. Segundo esse modelo, a inteligência é um caso particular de adaptação biológica. Um organismo adaptado ao meio é aquele que mantém um equilíbrio em suas trocas com o meio. Ou seja, é aquele que interage com o ambiente mantendo um equilíbrio entre suas necessidades de sobrevivência e as dificuldades e restrições impostas pelo meio. Essa adaptação tonar-se possível graças aos processos de assimilação e de acomodação (que, juntos, constituem o mecanismo adaptativo), comum a todos os seres vivos. (FONTANA e CRUZ, 1997, p. 46)

Seguindo esse raciocínio, a criança se adapta cada vez melhor, em relação ao meio e amplia seus modos de agir e pensar diante das diversas situações que lhe são apresentadas. Portanto, percebese a complexidade que se faz presente no pensamento humano e como são essenciais tais processos de assimilação e acomodação.

Vygotsky (1998), em sua teoria, considera o desenvolvimento infantil por meio de três aspectos: o instrumental, o cultural e o histórico e faz relação entre desenvolvimento, aprendizagem e escola. Destaca-se, aqui, o conceito de mediação e a Zona de Desenvolvimento Proximal.

Lev Semenovich Vygotsky enfatiza na sua teoria que grande parte do desenvolvimento humano se faz através da contribuição das relações sociais, as quais promovidas pelo o meio são fontes para a construção da mente humana ao propiciarem, desta forma, o desenvolvimento do indivíduo. O homem e o meio são influência entre si e o homem aprende a ser homem através dessa influência. 
Vygotsky (1998), em sua teoria, faz relação entre desenvolvimento, aprendizagem e a escola. Esse olhar para a Educação deve-se a ênfase que direciona a mediação. Para esse teórico, 0 desenvolvimento acontece de fora para dentro, pois o indivíduo está, desde o seu nascimento, imerso em um mundo linguístico e cultural, no qual a aprendizagem denota caminhos para que o seu desenvolvimento seja promovido, em relação à cultura da sociedade em que esse indivíduo está inserido.

Para Fontana e Cruz, sobre a relação aprendizagem e desenvolvimento, é essencial destacar que:

Embora aponte diferenças entre aprendizado e desenvolvimento, Vygotsky considera que esses dois processos caminham juntos desde o primeiro dia da vida da criança e que o primeiro - o aprendizado - suscita e impulsiona o segundo - o desenvolvimento. Ou seja, tudo aquilo que a criança aprende com o adulto ou com outra criança mais velha vai sendo elaborado por ela, vai se incorporando a ela, transformando seus modos de agir e pensar. (1997, p. 63).

Entretanto, esse aprendizado pode ocorrer com a mediação de outras crianças ou através de um adulto. Logo, percebe-se que os processos de mediação e internalização, sempre quando entrelaçados, oportunizam o desenvolvimento da criança ao propiciar situações de aprendizagem influenciadoras no desenvolvimento. A intenção é promover a ação da criança com mais independência, em relação as mesmas situações em que antes era necessário auxílio.

Em relação a zona de desenvolvimento proximal Vygotsky expõe que:

(...). Ela é a distância entre o nível de desenvolvimento real, que se costuma determinar através da solução independente de problemas, e o nível de desenvolvimento potencial, determinado através da solução de problemas sob orientação de um adulto ou em colaboração com companheiros mais capazes. (1998, p. 112).

Na teoria Walloniana, o estágio do personalismo (dos 3 aos 6 anos) possui três períodos: de oposição (3 aos 4 anos), de sedução (dos 4 aos 5 anos) e de imitação (5 aos 6 anos), nos quais ocorre um avanço na autoafirmação e no desenvolvimento intelectual, segundoTourrette (2012).

Henri Wallon, possui um foco diferenciado dos demais teóricos por enxergar o ser humano através da integralidade (afetividade, motricidade e inteligência) que possuiu papel indissociável, para esse, na formação do indivíduo como pessoa. Analisa o ser humano contextualizado com o seu meio social e cultural ao caracterizar sua teoria como interacionista.

Em relação a linha de raciocínio de Wallon sobre o desenvolvimento da criança, Gratiot-Alfandéry explica que:

(...). Ele contribui ao iluminar com outro foco como se dão as passagens de um momento a outro do processo de desenvolvimento: a criança passará por diferentes fases, cuja superação se dará por meio da vivência de uma ruptura, ou, nas palavras do autor, de uma crise. Nesse sentido, para Wallon, esse momento de ruptura é de fundamental importância e deve ser valorizado, uma vez que, tendo acumulado experiências e desenvolvido outros recursos, em determinado momento o sujeito necessita haver-se com essas coisas para garantir seu processo de individuação e autonomização. (...). (2010, p.40).

Para esse teórico, as fases do desenvolvimento humano ocorrem por meio da influência de sentimentos dominados em determinada fase pela afetividade ou pela cognição. Porém, é válido 
esclarecer que mesmo com esse predomínio momentâneo ambos aspectos, afeto e cognição, permanecem em pleno desenvolvimento atrelados aos demais.

Ressalta-se, na referida teoria, que cada estágio suscita o seguinte e esse não exclui o anterior e sim reformula-o, esses permanecem interligados durante a evolução do desenvolvimento, o qual ocorre de maneira contínua por meio de processos alternados, tanto para o mundo interno quanto para o mundo externo.

De acordo com Bee (2011), o estágio fálico (dos 3 aos 5 anos) da teoria Freudiana é um período dinâmico da vida infantil, não apenas pelas descobertas sobre o próprio corpo, mas também pela aquisição dos valores morais, ressalta-se aqui, o Complexo de Édipo.

Freud revolucionou o modo de pensar o desenvolvimento humano. Enfatiza que muitos dos acontecimentos ocorridos na infância são traços para o comportamento na vida adulta. A busca pelo prazer, no sentido de satisfação, faz parte do desenvolvimento humano na teoria freudiana, porque o indivíduo possui necessidades e desejos peculiares. Um ponto importante para compreender a psicanálise é o papel da libido e a sua influência no desenvolvimento humano.

Em relação a libido Tourrette, esclarece que:

(...). Ela representa a energia derivada das pulsões sexuais que vai distribuir-se, diferentemente, à medida do desenvolvimento da criança. Eis porque Freud fala de desenvolvimento libidinal. A libido investe, a um só tempo, o próprio sujeito (narcisismo) ou os objetos. Tais objetos do desenvolvimento pulsional podem ser uma pessoa, o próprio sujeito ou uma coisa. Indiquemos, com precisão, de saída, que a sexualidade da criança, abordada por Freud, não é a sexualidade genital do adulto: esse conceito é considerado no sentido amplo do prazer associado à satisfação das pulsões (...). A origem das pulsões é essencialmente corporal e a maturação do corpo determina a maturação das pulsões. O desenvolvimento pulsional está, assim, estreitamente associado à sucessão das zonas erógenas (as que provocam um prazer libidinal), no decorrer do desenvolvimento da criança. (2012b, p. 30).

Esse período da vida infantil é dinâmico não apenas pelas descobertas sobre o próprio corpo, mas também pelas várias situações conquistadas nessa etapa. A aquisição da linguagem e o movimento, cada vez mais elaborados, oportunizam novas formas de expressão usadas, em especial, no ambiente escolar.

No que diz respeito a aquisição dos valores morais Bock, Furtado e Teixeira afirmam "O superego origina-se com o complexo de Édipo, a partir da internalização das proibições, do limite e da autoridade. A moral, os ideais são funções do superego. O conteúdo do superego refere-se a exigências sociais e culturais. " (2008, p. 52).

Os pais ou o professor serão pontos de referência em relação a aprendizagem das regras e valores morais. Logo, a escola e o meio produzirão uma ampliação da socialização. Todos esses fatores interligados constituem um novo modo de se enxergar no mundo e como consequência provocam mudanças no comportamento.

Sobre o Complexo de Édipo, detalhe peculiar da teoria freudiana, Tourrette explicita que:

(...). Nesse momento, a criança acaba de sair da relação dual com a mãe e deve levar em consideração a relação entre o pai e a mãe; portanto, ela deve-se inserir-se em uma relação, triangular. Esse complexo descreve o amor da criança pelo genitor do 
sexo oposto, acompanhado pelo desejo de morte em relação ao outro genitor (do mesmo sexo); de fato, este é percebido como um obstáculo ao amor da criança pelo genitor escolhido. (...). Ao dar-se conta de que seus esforços para ser o único eleito no coração da mãe não surtem efeito já que o pai mantém, igualmente, sua posição junto à mãe, o menino renuncia a conquistá-la, identificando-se com o pai pela interiorização dos interditos parentais; em seguida, voltar-se-á de maneira cada vez mais frequente para objetos de substituição. (...). (2012a. p. 180).

As teorias não apresentam maneiras de como lidar com o aluno em sala de aula, porém, ampliam o conhecimento do professor. Tal conhecimento influenciará na compreensão que esse profissional terá sobre os modos singulares em que a criança percebe, compreende e atua sobre o mundo em que está inserida.

\section{METODOLOGIA}

Inicialmente foi realizada a pesquisa bibliográfica com o objetivo de levantar as principais referências teóricas publicadas sobre o assunto.Para a pesquisa foi escolhida a pesquisa de abordagem qualitativa, por ser a mais indicada para esta investigação. A pesquisa qualitativa em educação enfatiza o processo, aquilo que está ocorrendo, e não o produto ou os resultados finais. Uma outra característica interessante desse tipo de abordagem é que a pesquisa se refaz constantemente no próprio processo de investigação.

No que se refere à abordagem qualitativa, Minayo discorre que:

A pesquisa qualitativa responde a questões muito particulares. Ela se ocupa, nas Ciências Sociais, com um nível de realidade que não pode ou não deveria ser quantificado. Ou seja, ela trabalha com o universo dos significados, dos motivos, das aspirações, das crenças, dos valores e das atitudes. Esse conjunto de fenômenos humanos é entendido aqui como parte da realidade social, pois o ser humano se distingue não só por agir, mas por pensar sobre o que faz e por interpretar suas ações dentro e a partir da realidade vivida e partilhada com seus semelhantes. (...). (2012, p. 21).

Para dar ressignificados aos fatos que vão sendo revistos, utiliza-se de um planejamento flexível e os fundamentos teóricos são repensados.

Os participantes foram três professoras de uma escola municipal localizada na cidade de Passos, Minas Gerais. A escola mencionada possui 490 alunos. Atende os níveis de ensino da Educação Infantil (pré-escola 4 e 5 anos de idade), Ensino Fundamental ( $1^{\circ}$ ao $5^{\circ}$ ano) e Educação de Jovens e Adultos (EJA) (10 ao $5^{\circ}$ ano), respectivamente, nos turnos vespertino, matutino/vespertino e noturno.

Inicialmente, foram selecionadas três escolas, porém, somente a escola citada demonstrou interesse em participar. A instituição era de fácil acesso em relação a localização fator positivo para a pesquisa. A diretora da referida escola deu o acolhimento necessário para que fosse realizada a pesquisa de campo, assinando o Termo de Anuência.Logo, todos esses aspectos tornaram viáveis sua escolha.

A escolha das três professoras não foi aleatória: como critério, deveriam ser professores da Educação Infantil (pré-escola - 5 anos de idade) e do $1^{\circ}$ ano do Ensino Fundamental. Essas profissionais foram selecionadas devido à disponibilidade em participar da pesquisa. 


\subsection{Instrumentos}

Iniciou-se, portanto, a pesquisa através de estudos bibliográficos descritivos, sobre a Educação Infantil, o Ensino Fundamental e as teorias do desenvolvimento humano.Com o objetivo de capturar as mudanças em processo e as práticas pedagógicas utilizadas no cotidiano, a presente pesquisa utilizou instrumentos como a entrevista estruturada e a observação participante, com o intuito de compreender as relações, o processo pedagógico escolar, vivências, estudo das práticas, hora de recreio e outras situações.

De acordo com Minayo:

(...). Entrevista é acima de tudo uma conversa a dois, ou entre vários interlocutores, realizada por iniciativa do entrevistador. Ela tem o objetivo de construir informações pertinentes para um objeto de pesquisa, e abordagem pelo entrevistador, de temas igualmente pertinentes com vistas a este objetivo. (2012, p. 64).

Diante de um roteiro com perguntas definidas, optou-se pela entrevista estruturada. As mesmas foram realizadas in loco, com datas definidas e foram realizadas individualmente.

Na observação participante, os aspectos a serem observados foram previamente definidos (entrada, processo de ensino e aprendizagem da sala de aula e em outros ambientes da escola, recreio e saída). O intuito era elaborar um banco de dados que contribuísse de maneira eficiente para a análise da situação pesquisada, ou seja, o processo de transição da Educação Infantil para o Ensino Fundamental e a prática docente.

No que diz respeito à observação participante, Minayo destaca que:

A observação participante pode ser considerada parte essencial do trabalho de campo na pesquisa qualitativa. Sua importância é de tal ordem que alguns estudiosos a consideram não apenas uma estratégia no conjunto da investigação das técnicas de pesquisa, mas como um método que, em si mesmo, permite a compreensão da realidade.

Definimos observação participante como um processo pelo qual um pesquisador se coloca como observador de uma situação social, com a finalidade de realizar uma investigação científica. (...). (2012, p. 70).

\subsection{Procedimentos de coleta dos dados}

Obtida a permissão da escola e das professoras, essas assinaram o Termo de Consentimento Livre e Esclarecido, Resolução número 466/2011 - IV, do Conselho Nacional de Saúde. A coleta de dados foi realizada na própria dependência da escola citada. Logo, a pesquisa de campo realizou-se entre os dias 04/05/2015 a 12/06/2015.

As entrevistas foram realizadas individualmente. Em relação à observação participante, ela ocorreu em um período estabelecido de tempo (cinco dias) para cada uma das três turmas pesquisadas.

\subsection{Procedimentos de análise dos dados}

Para análise dos dados, foram utilizadas ferramentas qualitativas do método de análise de conteúdo, partindo da análise temática do conteúdo gerado, que foram organizadas em: pré-análise (leitura 
compreensiva do conjunto do material selecionado), exploração do material (análise do material) e tratamento dos resultados e interpretação (síntese interpretativa que dialoga temas com os objetivos, questões e pressupostos da pesquisa), de acordo com Minayo (2012).

\section{RESULTADOS E DISCUSSÃO}

O conhecimento sobre a importância do processo de transição da Educação Infantil para o Ensino Fundamental e, em especial, as práticas pedagógicas utilizadas pelas professoras participantes norteou a pesquisa.

Nesse contexto, as professoras entrevistadas se caracterizam da seguinte maneira: 1) Professora A: trabalha com uma turma da pré-escola (5 anos de idade) da Educação Infantil com 19 alunos. Tem 8 anos de docência, dos quais 3 anos dedicou seu trabalho à pré-escola ( 5 anos de idade). Possui Magistério nível médio e curso de Pedagogia incompleto. 2) Professora B: trabalha com uma turma do $1^{0}$ ano do Ensino Fundamental com 20 alunos. Tem 35 anos de docência, dos quais 9 anos dedicou seu trabalho ao $1^{0}$ ano do Ensino Fundamental. Possui Magistério nível médio e graduação em Ciências Sociais, sem pós-graduação. 3) Professora C: trabalha com uma turma do $1^{0}$ ano do Ensino Fundamental com 20 alunos. Tem 5 anos de docência, dos quais 3 anos dedicou seu trabalho ao 10 ano do Ensino Fundamental. Possui Magistério nível médio e graduação em Matemática, sem pósgraduação.

Com base nos dados das entrevistas e da observação participante, emergiram dois eixos temáticos:1) Elementos constituintes da prática escolar, subdividido em: formação acadêmica e elaboração da prática docente, 2) Práticas e opiniões sobre os níveis de ensino, subdividido em: práticas pedagógicas adotadas em sala de aula e opiniões sobre a transição da Educação Infantil para o Ensino Fundamental.

\subsection{Elementos constituintes da prática escolar}

\subsubsection{Formação acadêmica}

A formação acadêmica do professor é de vital importância. Ela será um dos instrumentos essenciais para que esse profissional possa embasar sua prática em sala de aula. Portanto, a qualidade dessa formação inicial e a sua constante atualização serão pontos influenciadores na sua atuação em sala de aula.

Quando as professoras foram questionadas se o conhecimento adquirido na graduação e/ou Magistério oferecia uma base inicial que garantia a qualidade do processo de ensino e aprendizagem em sala de aula, todas declararam que sim, devido ao fato de participarem dos programas de formação continuada oferecido pelo município ao qual a escola pertence.

Sobre essa pergunta a professora A declara que:

Sim. Porque quando necessário busco novos conhecimentos e aperfeiçoamento na minha área de atuação profissional. A capacitação constante dificulta os erros e proporciona um olhar crítico, reflexivo e maleável capaz de promover mudanças em nossa prática pedagógica para atender melhor às necessidades dos nossos alunos, aumentando a qualidade de ensino e aprendizagem. 
Nota-se que essas professoras atrelam a sua formação acadêmica inicial à formação continuada com o intuito de agregar mais conhecimento para enriquecer sua prática pedagógica.

Nas palestras e cursos de formação continuada são ressaltados assuntos diversificados sempre trazendo o que há de mais novo na área educacional e destaca-se a importância de se considerar a fase do desenvolvimento humano em que a criança se encontra. Nesse contexto, a teoria de Piaget é por diversas vezes relembrada, por ser a teoria embasada nos programas de educação do Município.

Tal atitude se faz eficaz no processo de transição da Educação infantil para o Ensino Fundamental, porque se renovam os conhecimentos, métodos e didáticas, o que gera a otimização da prática pedagógica do docente no processo de ensino e aprendizagem. Observou-se nas atividades de sala de aula que, nesse contexto, para o professor, tão importante quanto adquirir novos conhecimentos é aprender a aplicá-los, levando em consideração às especificidades de cada nível de ensino.

\subsubsection{Elaboração da prática docente}

Um dos conhecimentos pertinentes adquiridos na formação inicial de professores são as diversas teorias sobre o desenvolvimento humano, de acordo com o Projeto Político Pedagógico do curso de formação de professores, da universidade em que as professoras pesquisadas obtiveram sua graduação. Quando questionadas se seguiam alguma concepção/teoria do desenvolvimento humano e cognitivo da criança, as três entrevistadas foram unânimes em afirmar que focam sua prática na teoria de Piaget.

Nesse contexto, a professora B afirma que:

Sim, sigo os fundamentos da teoria de Piaget. Porém, só metodologias de ensino não são suficientes, o professor deve usar sua sensibilidade para interpretar as necessidades dos alunos com dificuldade.

Observa-se, por meio das entrevistas e da observação das práticas pedagógicas utilizadas, que, além de seguirem a teoria piagetiana, as professoras levam em conta, no processo de ensino e aprendizagem, a emoção. Consideram que é imprescindível, ao aliar prática e teoria, acrescentar um olhar atento às singularidades dos alunos. As professoras destacam que a aprendizagem sobre a teoria piagetiana fornecida em sua formação inicial são utilizadas em sua atuação como profissional e na elaboração das atividades que serão realizadas em sala de aula.

A teoria de Piaget amplia o conhecimento sobre a criança e sobre os processos de construção da inteligência. Dessa maneira, tal conhecimento disponibiliza meios para que o professor elabore com maior competência sua prática.

Sobre a prática e a teoria, Fontana e Cruz (1997, p. 70) discorrem que:

A prática é a base da teoria (que também é uma prática humana de produção de conhecimento). E a teoria elaborada é uma reflexão organizada e sistematizada sobre aspectos da prática que nos ajudam a analisá-la, problematizá-la e redefini-la. Nesse sentido, teoria e prática articulam-se dinamicamente.

Percebeu-se, por meio da observação participante, que o brincar é valorizado pela equipe pedagógica da escola com a intenção de enriquecer a prática educativa. Durante o recreio, que tem a duração de quinze minutos, as crianças realizam brincadeiras junto aos seus pares, livres ou dirigidas pelos 
funcionários responsáveis pela inspeção. As brincadeiras utilizam bolas, cordas e cantigas de roda. A brincadeira varia de acordo com o nível de ensino. Por meio da brincadeira a função simbólica, que surge no estágio pré-operatório (dos 2 aos 7-8 anos) da teoria de Piaget, é construída e ampliada.

Na pré-escola (5 anos de idade) os momentos de brincadeiras, livres ou acrescidas de conteúdo pedagógico, na sala de aula, no pátio e no parquinho, desenvolvem a socialização, a imaginação e a motricidade. No $1^{0}$ ano do Ensino Fundamental, jogos e brincadeiras contendo conteúdos pedagógicos são utilizados, em sua maioria, dentro da sala de aula. Os jogos e brincadeiras com função de socializar, de ensinar regras e trabalho em equipe podem ser desenvolvidos na aula de Educação Física.

Brincar é, sem dúvida, uma forma de aprender, mas é muito mais que isso. Brincar é experimentar-se, relacionar-se, imaginar-se, expressar-se, compreender-se, confrontar-se, negociar, transformar-se, ser. Na escola, a despeito dos objetivos do professor e de seu controle, a brincadeira não envolve apenas a atividade cognitiva da criança. Envolve toda a criança. É prática social, atividade simbólica, forma de interação com o outro. Acontece no âmago das disputas sociais, implica a constituição do sentido. É criação, desejo, emoção, ação voluntária (FONTANA e CRUZ, 1997, p. 139).

Nos relatos das entrevistas, uma questão indagada foi se planejam as atividades práticas de acordo com a fase em que a criança se encontra. As respostas foram afirmativas.

A professora B explicita que:

Sim. Alguns alunos assimilam rápido o que Ihes foi passado, outros demoram um pouco. Por isso, observo os erros dos alunos e faço a interferência. Trabalho os conteúdos da seguinte maneira: introduzo, retomo, trabalho e consolido. Contudo, a parceria família e escola precede o desenvolvimento do aluno.

Nota-se que, tão importante quanto dominar o conhecimento sobre a teoria do desenvolvimento humano de Piaget, é aplicá-lo em sala de aula. Observou-se que, entender as especificidades da fase em que a criança se encontra, auxilia as professoras a elaborem atividades, com a intenção de alcançar objetivos específicos no processo de ensino e aprendizagem. Sendo assim, compreender todas as especificidades do estágio pré-operatório (dos 2 aos 7-8 anos) dá ao docente a percepção de como as crianças compreendem o mundo em que estão inseridas. Logo, fazendo uso dessa percepção as atividades elaboradas pelo professor consideram as limitações dos alunos.

Dessa maneira, o tempo de aprendizagem dos alunos é respeitado, ao mesmo tempo em que é suscitada a viabilização de sua evolução pelo professor, para que o desenvolvimento das crianças seja gradual e contínuo em todos os aspectos. Além disso, o planejamento e a aplicação das atividades ajudam o professor a encontrar a dificuldade de seus alunos e a avaliar a sua própria prática profissional.

Ainda sobre a prática e a teoria, Fontana e Cruz (1997, p. 70) destacam que:

Certamente o modo como o professor lida com a complexidade da prática é determinado pela compreensão que ele tem sobre ela, podendo essa compreensão ser instrumentalizada e mediada pela teoria. Nesse sentido, dizemos que o professor não aplica teorias, mas articula teoria e prática, à medida que seus conhecimentos teóricos o ajudam a compreender o que ocorre em sala de aula, marcando suas decisões e seus modos de agir. 


\subsection{Práticas e opiniões sobre os níveis de ensino}

\subsubsection{Práticas pedagógicas adotadas em sala de aula}

Nas observações do cotidiano escolar, percebeu-se que as práticas pedagógicas adotadas em sala de aula, são resultado da aliança entre teoria e prática proveniente da prática docente. Tais práticas levam em consideração a faixa etária dos alunos, a etapa de ensino e os conhecimentos que serão compartilhados.

Quando questionadas sobre quais as práticas pedagógicas propiciam a otimização do processo de transição da Educação Infantil para o Ensino Fundamental, as professoras descreveram as que consideram mais pertinentes.

As professoras $C$ e $B$, respectivamente, expõem que é necessário:

(...) aprender e desenvolver o conceito relacionado ao tempo de realização das atividades propostas, (...) a utilização de ilustrações nas atividades.

(...) tornar o aluno agente do processo de ensino e aprendizagem, analisar o aluno para saber o que ele já domina, construir regras de convivência social com os alunos, enfatizar o trabalho coletivo, oferecer as informações necessárias para a construção do conhecimento e a avaliação contínua.

No relato das professoras e nas observações em sala de aula, nota-se que todas possuem uma visão longitudinal no que se refere à formação do aluno para as etapas seguintes de ensino. Nesse contexto, as atividades elaboradas pelas professoras levam em consideração as características do estágio em que as crianças se encontram: pré-operatório (dos 2 aos 7-8 anos). Desse modo, contribuem para a aprendizagem de regras e valores e para a assimilação e acomodação de conceitos e conhecimentos de maneira mais produtiva, os quais serão a fundamentação para o desenvolvimento das especificidades do estágio seguinte.

As professoras procuram devolver habilidades e competências necessárias na etapa de ensino em que as crianças se encontram, sem deixar de introduzir saberes que serão ampliados e consolidados na próxima etapa. Além disso, consideram importante a parceria contínua entre família e escola e a utilização de jogos e brincadeiras.

As práticas pedagógicas usadas propiciam a utilização do conhecimento como ponto de ancoragem para a construção de novos saberes. Essas práticas têm previamente definidas as didáticas e metodologias que serão empregadas.

Em relação ao processo de ensino e aprendizagem, Perrenoud (2000, p. 26) explicita que:

Conhecer os conteúdos que serão ensinados é a menor das coisas, quando se pretende instruir alguém. Porém, a verdadeira competência pedagógica não está aí; ela consiste, de um lado, em relacionar os conteúdos aos objetivos e, de outro lado, a situações de aprendizagem. (...).

Nesse contexto, na observação participante, notou-se que, quando necessário, as professoras diversificam as metodologias e didáticas utilizadas no ensino dos componentes curriculares. A professora A tem na interdisciplinaridade um ponto referencial para trabalhar todos os eixos exigidos na Educação Infantil: faz uso da ludicidade e utiliza materiais diversificados para promover uma 
aprendizagem no concreto, elabora atividades e utiliza a apostila disponibilizada pela Secretaria de Educação do município.

As professoras B e C fazem uso do livro didático disponibilizado pelo MEC, possuem um ambiente alfabetizador em suas salas e fazem uso da ludicidade, de jogos e brincadeiras, visando uma melhor aprendizagem. Desse modo, as professoras auxiliam as crianças na ampliação do plano representativo por meio da construção da função simbólica e ajudam na superação do egocentrismo, características do estágio pré-operatório (dos 2 aos 7-8 anos).

Além disso, a gestão da escola procura envolver todos os seus participantes, sem deixar de incluir seus influenciadores externos (família e comunidade) que integram o ambiente escolar por meio da bagagem cultural do aluno, para a viabilização de um processo de ensino e aprendizagem de qualidade.

\subsubsection{Opiniões sobre a transição da Educação Infantil para o Ensino Fundamental}

Ao finalizar a entrevista, foi perguntado às professoras se elas teriam algo a acrescentar sobre a temática da pesquisa. Diante disso, elas expuseram suas impressões sobre a transição da Educação Infantil para o Ensino Fundamental:

Em relação à transição desses dois níveis de ensino, acredito que não há ruptura, sempre avanço. (...). Se o professor trabalhar bem o planejamento, consolidar 0 alfabeto e regras de disciplina, a aprendizagem do aluno produzirá resultados positivos (Professora B).

A transição da Educação Infantil para o Ensino Fundamental deve acontecer de forma natural, o processo de aprendizagem deve ser contínuo. O lúdico deve estar presente aliado às novas práticas pedagógicas para que sejam atingidos os objetivos propostos (Professora A).

Observa-se que as professoras pesquisadas destacam que o processo de transição deve acontecer de forma natural, porque faz parte do percurso da vida escolar.

Nesse contexto, elas expõem que a ludicidade deve estar presente nos dois níveis de ensino e que o uso de atividades lúdicas deve ser reelaborado à medida que acontecem as progressões nas etapas de ensino. O intuito é fazer uso do lúdico como aliado à construção do conhecimento, de maneira planejada e quando for necessário.

Educação infantil e ensino fundamental são frequentemente separados. Porém, do ponto de vista da criança, não há fragmentação. Os adultos e as instituições é que muitas vezes opõem educação infantil e ensino fundamental, deixando de fora o que seria capaz de articulá-los: a experiência com a cultura. Questões como alfabetizar ou não na educação infantil e como integrar educação infantil e ensino fundamental continuam atuais. Temos crianças, sempre, na educação infantil e no ensino fundamental. Entender que as pessoas são sujeitos da história e da cultura, além de serem por elas produzidas, e considerar os milhões de estudantes brasileiros de 0 a 10 anos como crianças e não só estudantes, implica ver o pedagógico na sua dimensão cultural, como conhecimento, arte e vida, e não só como algo instrucional, que visa a ensinar coisas. Essa reflexão vale para a educação infantil e o ensino fundamental. (KRAMER, 2007, p. 19-20). 
Constata-se, assim, a importância de conhecer o nível de conhecimentos adquiridos pelas crianças na etapa de ensino anterior. Tal atitude auxilia o professor em sua prática pedagógica. Desse modo, é essencial não perder o foco dos objetivos que devem ser alcançados em cada fase escolar.

Sendo assim, a transição deve ser vivenciada com naturalidade. Os professores da Educação Infantil e do Ensino Fundamental, pais e escola são influenciadores entre si. Logo, têm a função de preparar as crianças para as mudanças que envolvem cada etapa de ensino e auxiliar no avanço que será por elas proporcionado.

\section{CONSIDERAÇÕES FINAIS}

Percebeu-se, ao longo do trabalho, a relevância da elaboração da prática docente no processo ensinoaprendizagem, especificamente no processo de transição da Educação Infantil para o Ensino Fundamental. Essa elaboração tem, como algumas de suas ferramentas, a formação acadêmica inicial e a formação continuada. Nesse sentido, constata-se a urgência do professor em se manter atualizado no âmbito educacional, pois nele as mudanças são constantes. Apesar de não terem pós-graduação, elas participam constantemente dos cursos oferecidos pela Secretária Municipal de Educação, o que contribuiu para a prática pedagógica no cotidiano.

Dessa maneira, para se adaptar aos diferentes contextos que se apresentam em sala de aula, é necessário que o conhecimento do professor em relação às teorias, didáticas e metodologias, seja disponibilizado com qualidade em sua formação inicial e continuamente renovado. Nesse contexto, o conhecimento das teorias do desenvolvimento humano é indispensável à prática docente, porque o professor poderá lidar com diferentes faixas etárias, em diferentes níveis de ensino.

Constatou-se que esse conhecimento propicia ao docente a compreensão das especificidades da maturidade da criança e a forma como constrói o conhecimento. Portanto, tão essencial quanto conhecer, é aplicar, com competência e por meio de suas práticas pedagógicas, as contribuições da teoria do desenvolvimento humano de Piaget.

Entretanto, é essencial levar em consideração no processo de ensino e aprendizagem a bagagem cultural, os aspectos emocionais, econômicos e sociais que envolvem seus alunos. Outra atitude importante é não excluir do ambiente escolar seus influenciadores externos (família e comunidade) que integram de maneira ímpar a escola por meio da bagagem cultural dos alunos, pois também possuem responsabilidade no desenvolvimento das crianças. Além disso, entrelaçar todos esses componentes permite elaborar um planejamento de acordo com a realidade da sala de aula e com os objetivos que devem ser alcançados em cada nível de ensino.

Dessa forma, o professor enriquece sua prática pedagógica e permite que sua intervenção, no processo de ensino e aprendizagem produza resultados positivos.

Portanto, planejar as práticas pedagógicas tendo como embasamento as contribuições das teorias do desenvolvimento humano piagetiana, demonstra uma visão longitudinal no que se refere à progressão na vida escolar por parte do docente, que vê a escola não apenas como um espaço de instrução, mas como uma instituição social, com função de formar cidadãos reflexivos e críticos, capazes de agir com autonomia e responsabilidade na sociedade. 


\section{REFERÊNCIAS}

BEE, Helen. A criança em desenvolvimento. 9. ed. Porto Alegre: Editora Artmed, 2011.

BOCK, Ana Maria Bahia; FURTADO, Odair; TEIXEIRA, Maria de Lourdes Trassi. Psicologias: uma introdução ao estudo de psicologia. 14. ed. São Paulo: Saraiva, 2008.

BORBA, Ângela Meyer. O brincar como um modo de ser e estar no mundo in Ministério da Educação - Secretária de Educação Básica. Ensino Fundamental de nove anos: orientações para a inclusão da criança de seis anos de idade. Brasília: Editora do Ministério da Educação, Secretaria de Educação Básica, 2007.

BRASIL. Ministério da Educação e do Desporto. Secretaria de Educação Fundamental. Referencial Curricular Nacional para a Educação Infantil. Brasília: MEC/SEF, 1998, v. 1.

BRASIL. Senado Federal. Lei de Diretrizes e Bases da Educação Nacional: no 9.394/96. Brasília: 1996.

FONTANA, Roseli e CRUZ, Maria Nazaré da. 1. ed. Psicologia e trabalho pedagógico. São Paulo: Atual, 1997.

GRATIOT-ALFANDÉRY, Hélène. Henri Wallon. 1. ed. Recife: Fundação Joaquim Nabuco, Editora Massangana, 2010.

KRAMER, Sonia. A infância e sua singularidade in Ministério da Educação - Secretária de Educação Básica. Ensino Fundamental de nove anos: orientações para a inclusão da criança de seis anos de idade. Brasília: Editora do Ministério da Educação, Secretaria de Educação Básica, 2007.

MINAYO, Maria Cecília de Souza. O desafio da pesquisa social in MINAYO, Maria Cecília de Souza; DESLANDES, Suely Ferreira; GOMES, Romeu. Pesquisa social: teoria, método e criatividade. 31. ed. Petrópolis, Rio de Janeiro: Vozes, 2012.

PERRENOUD, Philippe. Dez novas competências para ensinar. Porto Alegre: Artmed, 2000.

PIAGET, Jean. Epistemologia genética. 2 ed. São Paulo: Martins Fontes, 2002.

TOURRETTE, Catherine. O desenvolvimento das crianças em idade escolar in TOURRETTE, Catherine; GUIDETTI, Michèle. Introdução à psicologia do desenvolvimento: do nascimento à adolescência. 2. ed. Petrópolis, Rio de Janeiro: Editora Vozes, 2012.

VYGOTSKY, Lev Semenovich. A formação social da mente: o desenvolvimento dos processos superiores. 6. ed. São Paulo: Martins Fontes Editora, 1998.

Submissão: 05/06/2018

Aceito: $13 / 08 / 2018$

\section{AGRADECIMENTOS}

À Universidade do Estado de Minas Gerais (UEMG) - Unidade Passos e a Fundação de Amparo à Pesquisa do Estado de Minas Gerais (FAPEMIG) pelo apoio durante a pesquisa. 